\title{
Beyond Point Design: General Pattern to Specific Implementations
}

\author{
Joel Lachter \\ Summer L. Brandt \\ Garrett Sadler \\ R. Jay Shively
}

July 20, 2017 


\section{Talk Outline}

- Review of HAT Principles

- How implementing HAT could improve interaction with automation you use regularly:

- Navigation

- Photography

- Common themes for implementing HAT

- Design Patterns: Common Problem-Solution Pairs 


\section{Human-Machine Function Allocation}

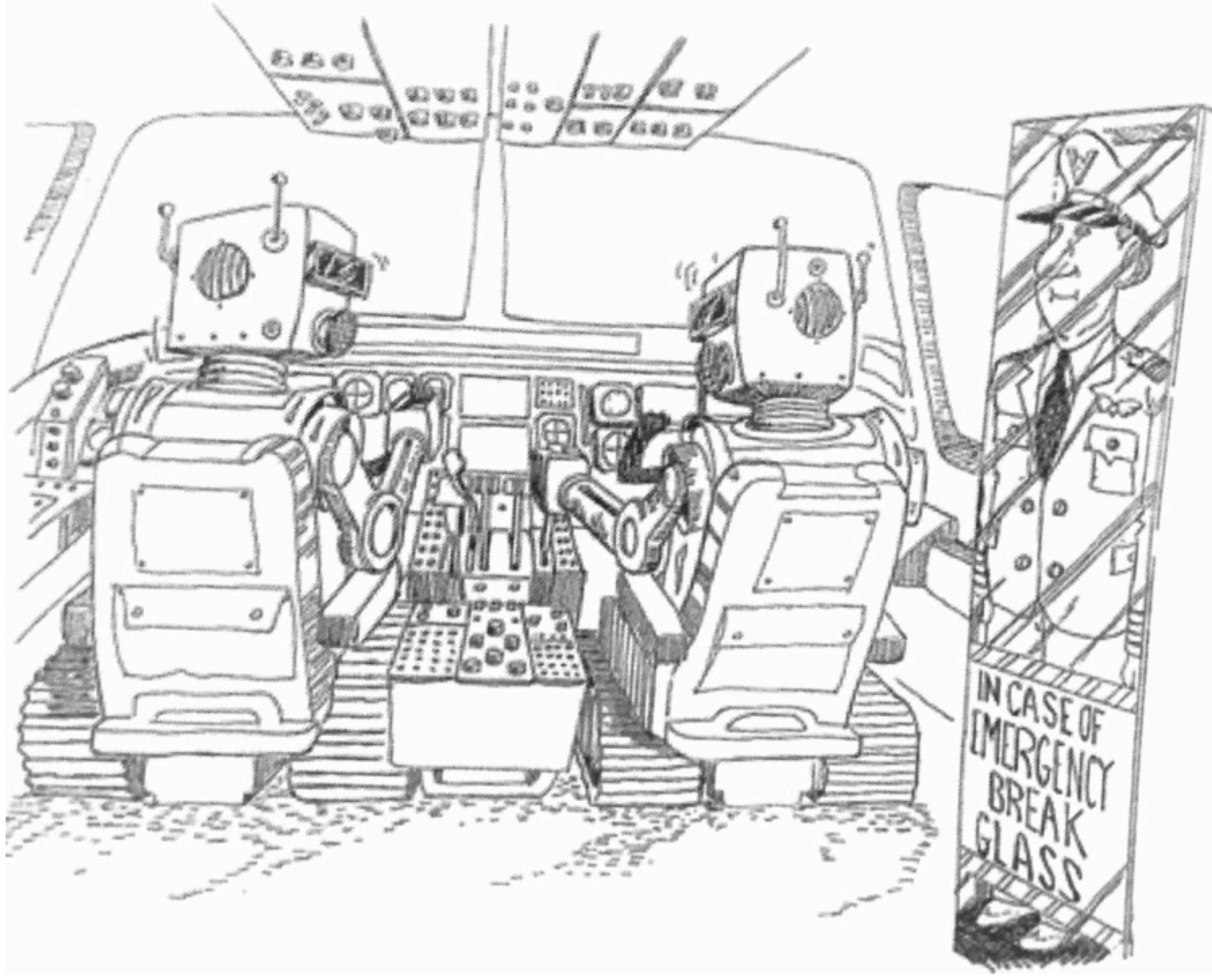




\section{Problems}

- Miscalibrated Trust

- People don't know when to break the glass

- Brittle

- You have to break the class

- Out-of-the-Loop Loss of Situation Awareness

- When you brake the glass, the pilot has no idea what is going on

- Opaque

- There is no easy way for the pilot to figure out what is going on

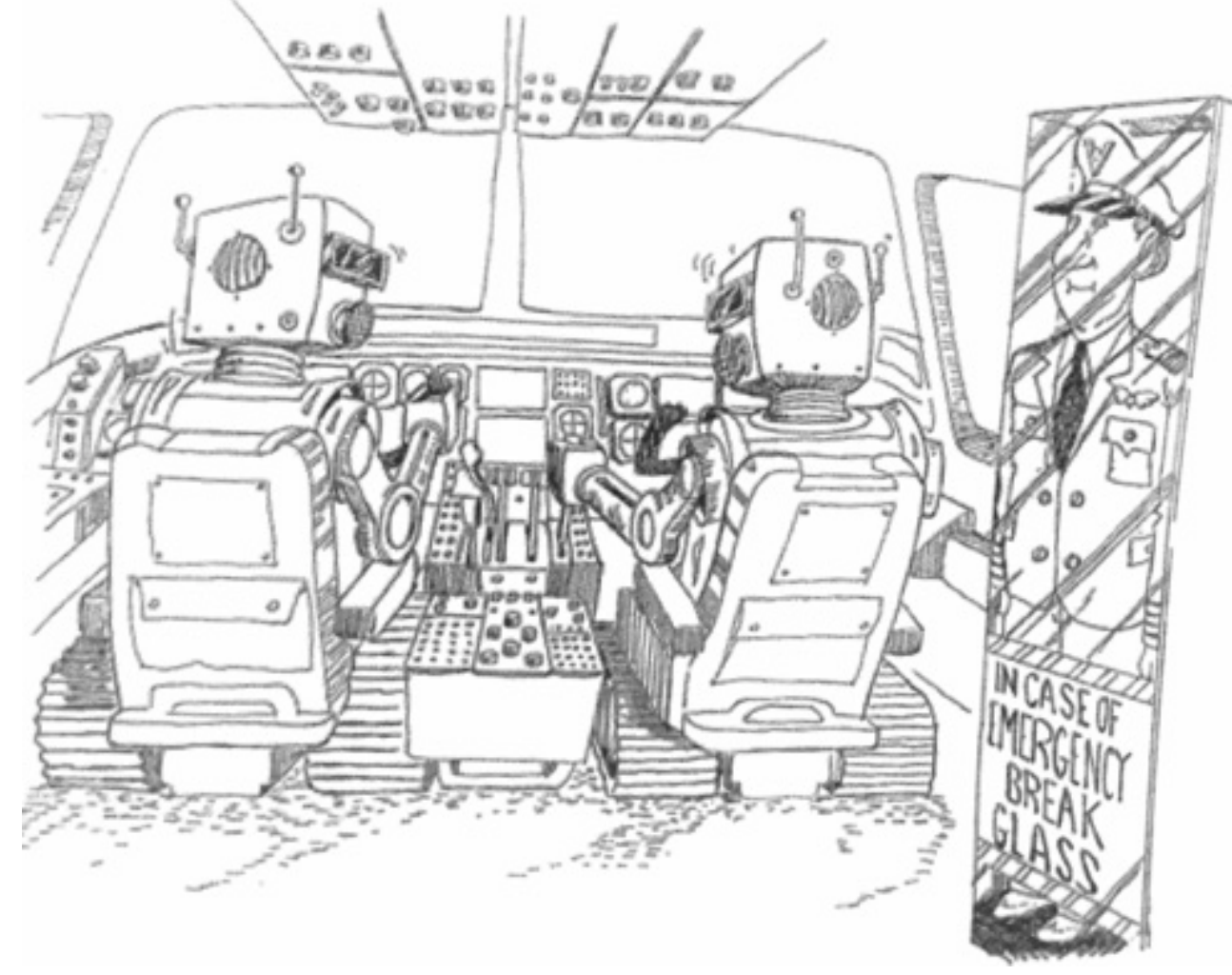




\section{Alternative: Make the Automation a Teammate}

Plays

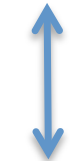

Standard

Operating

Procedures

\author{
Transparency \\ Communication of Rationale \\ Communication of Confidence \\ Shared Language \\ Shared Goals \\ Shared Plans \\ Shared Info About Threats \\ Agreed Allocation of Responsibility \\ Real Time Delegation \\ Minimized Intent Inferencing
}

\section{Bi-Directional \\ Communication}

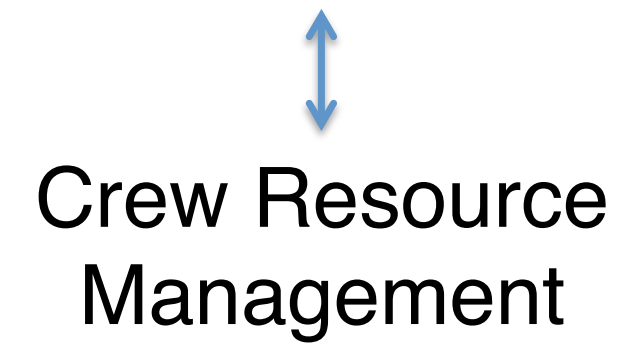




\section{HAT in Navigation}

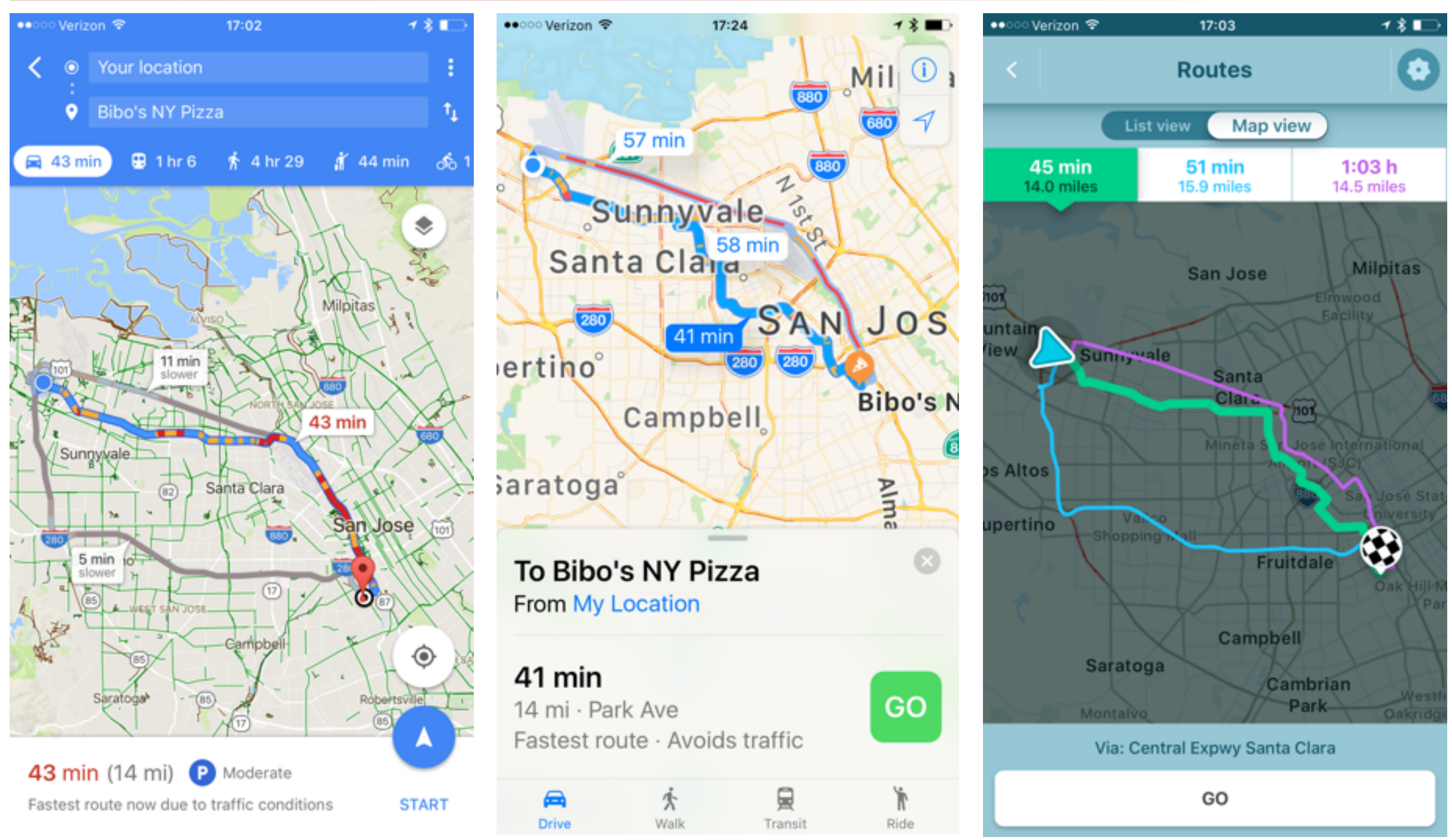




\section{HAT in Navigation}

\section{$2.5 \mathrm{mi}$ \\ Turn left onto Newhall St}

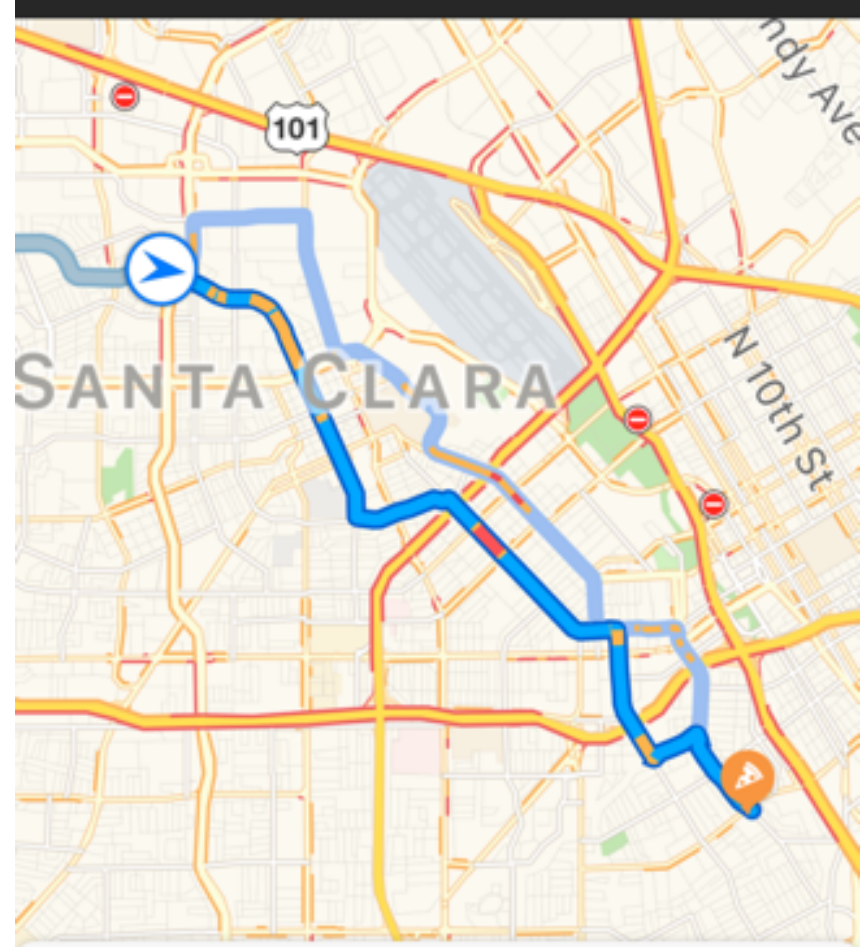

\section{Faster Route Available}

Save 2 min using The Alameda

Cancel

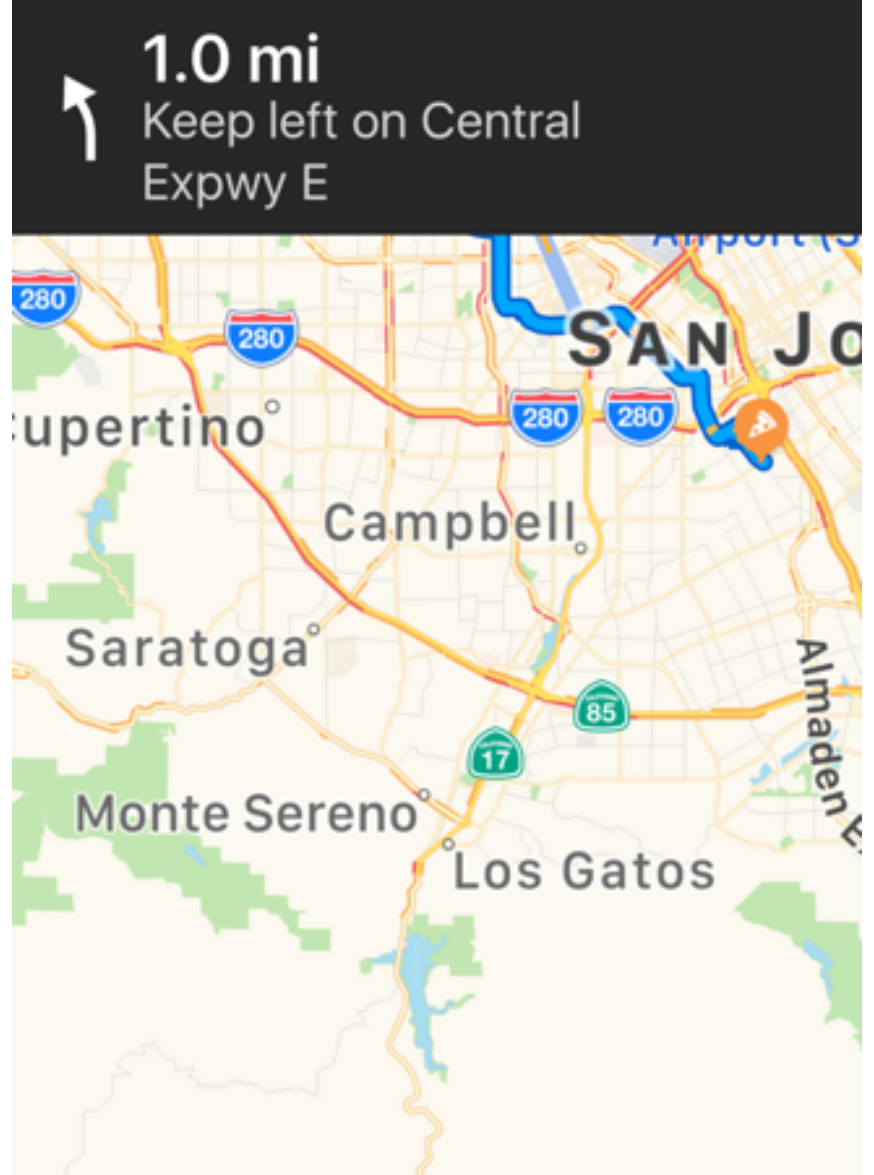

Faster Route Available

Save 16 min using Monroe St

Cancel

GO 


\section{HAT in Navigation}

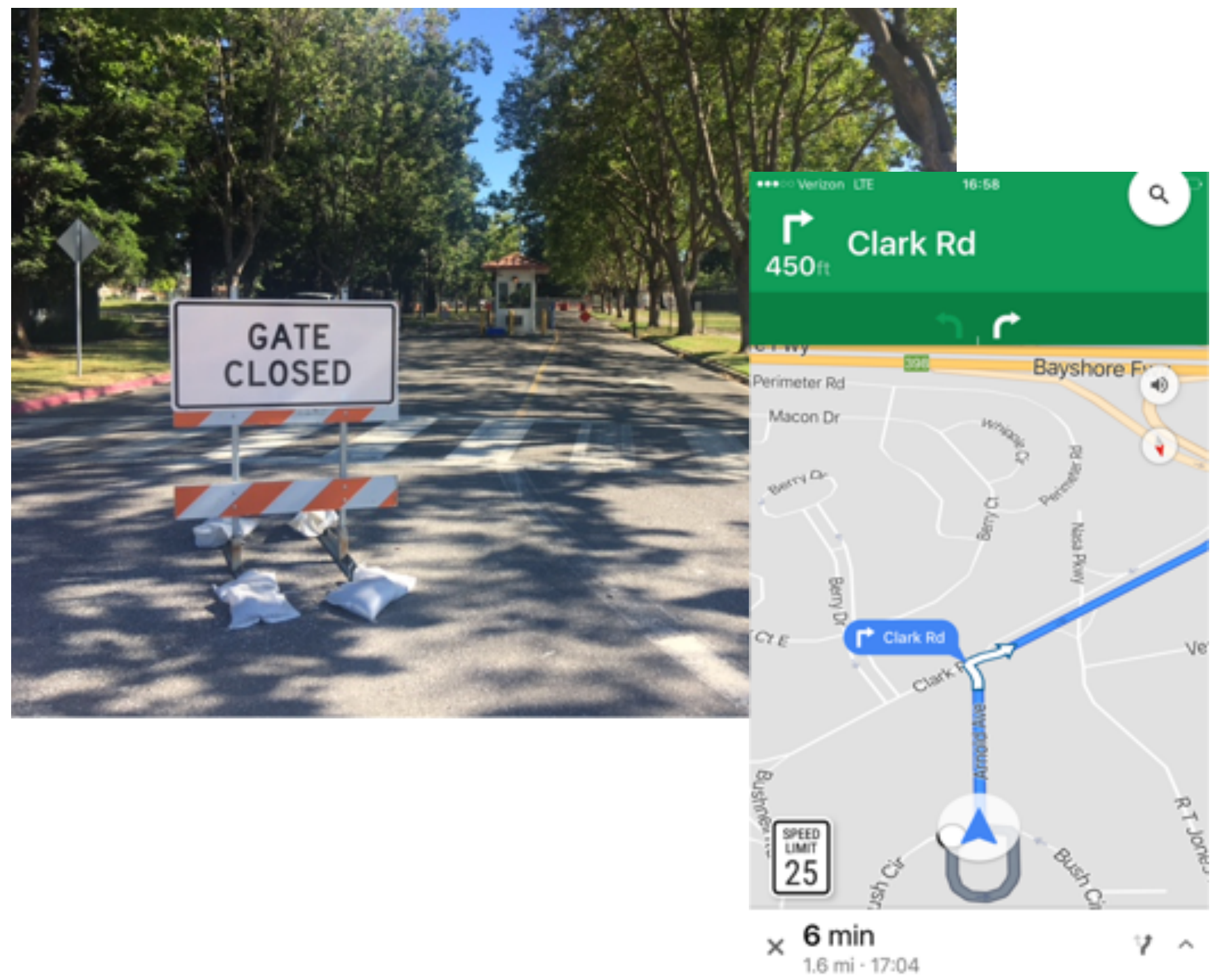




\section{HAT in Navigation}

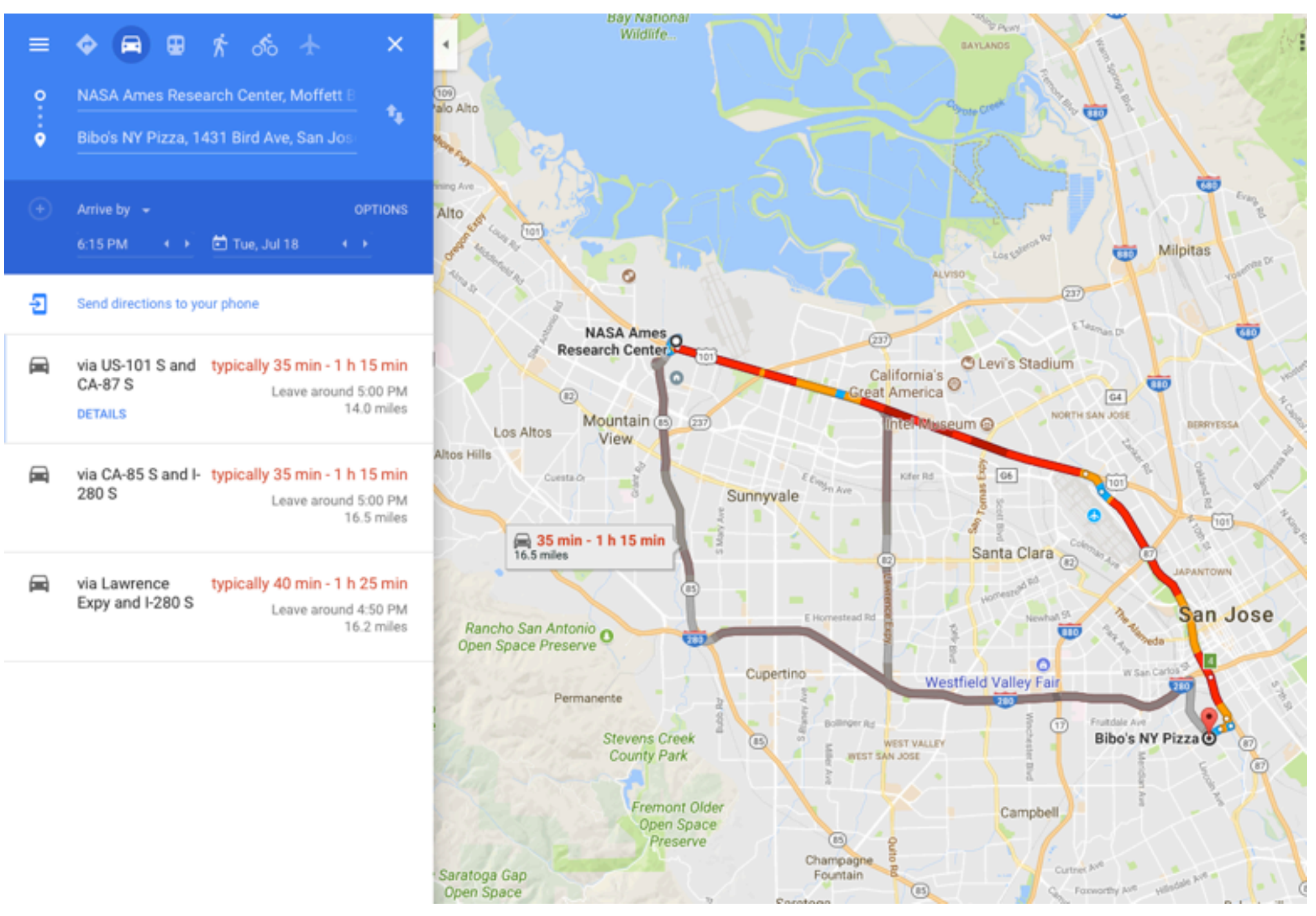




\section{HAT in Navigation}

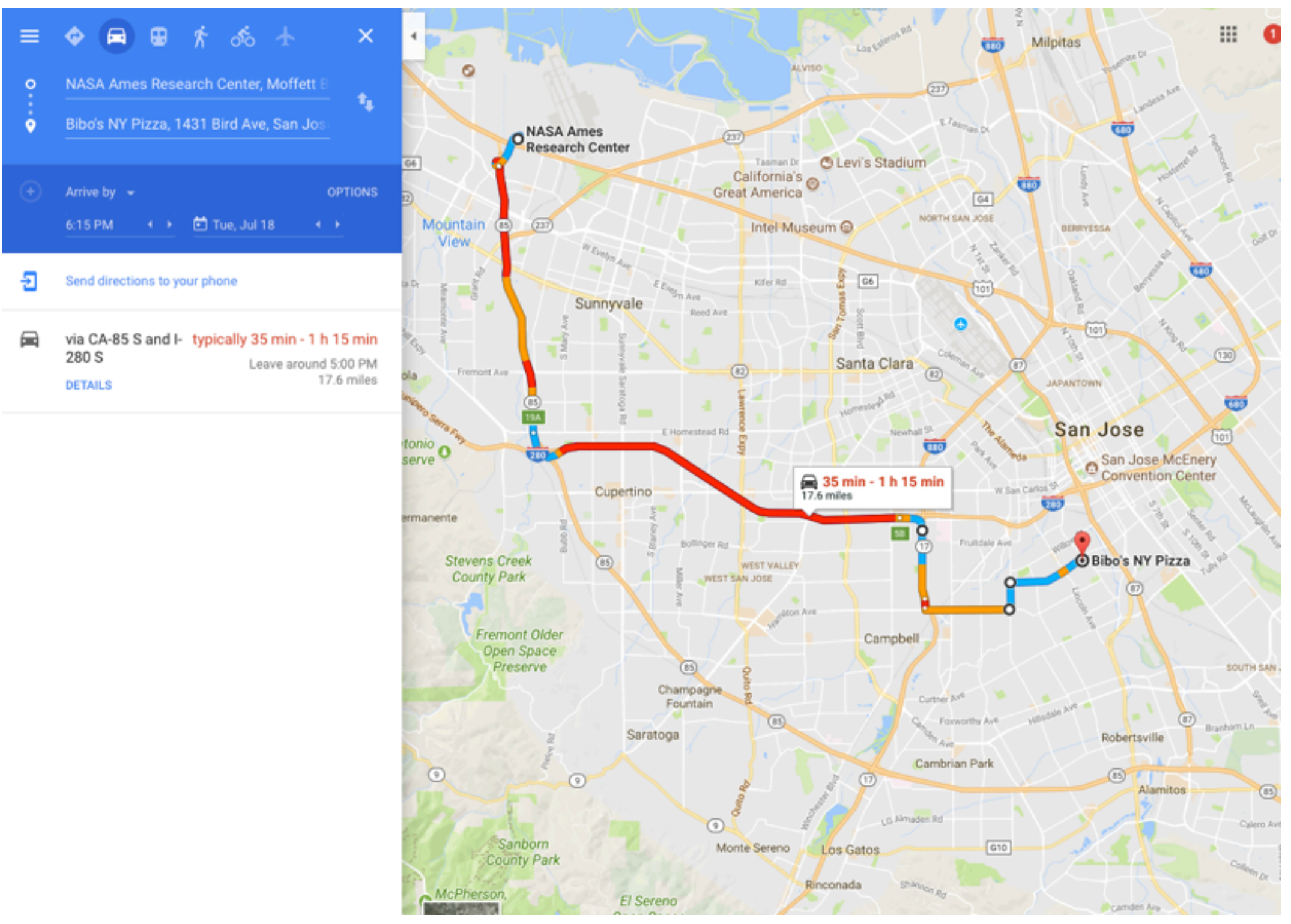




\section{HAT in Navigation}

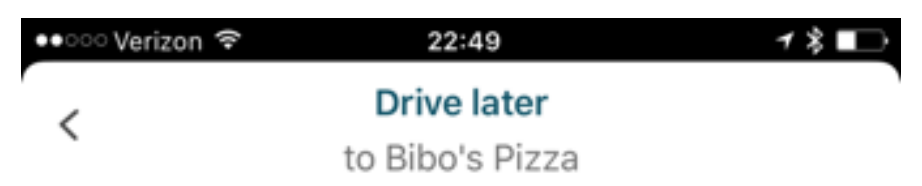

From Current location $\quad$
Day
Tue, Jul 18

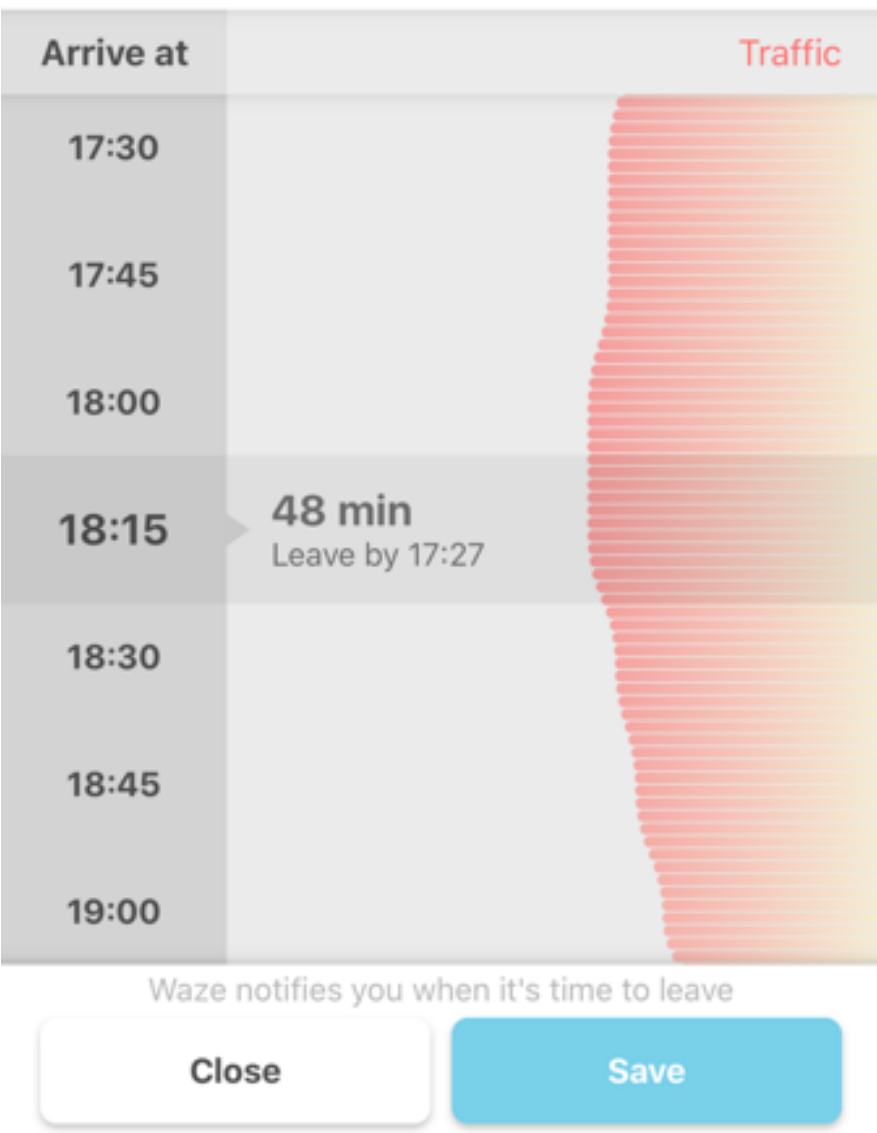

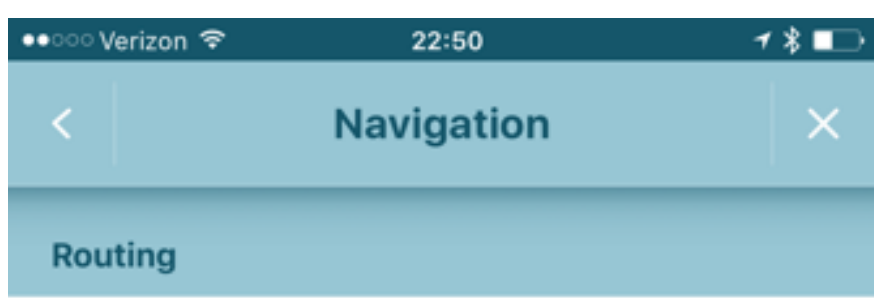

Avoid toll roads

Avoid freeways

Avoid ferries

Reduce difficult intersections

When possible, avoid difficult turns like junctions with no traffic light.

More options

Vehicle type

Private

Route type

Fastest

\section{Dirt roads}

Don't allow 


\section{HAT in Navigation}

\section{Routes $\rightarrow$ Plays}

- Specify alternate routes in advance

- Specify conditions for deviation from route

- E.g., only if it saves $>10$ minutes

- User can specify preferences

- I don't like surface streets

- I like 280 better than 101

- I am a carpool

\section{Bi-Directional Communication}

- Why is it choosing this route?

- If I have a route specified in advance automation can use a common language to inform me about it

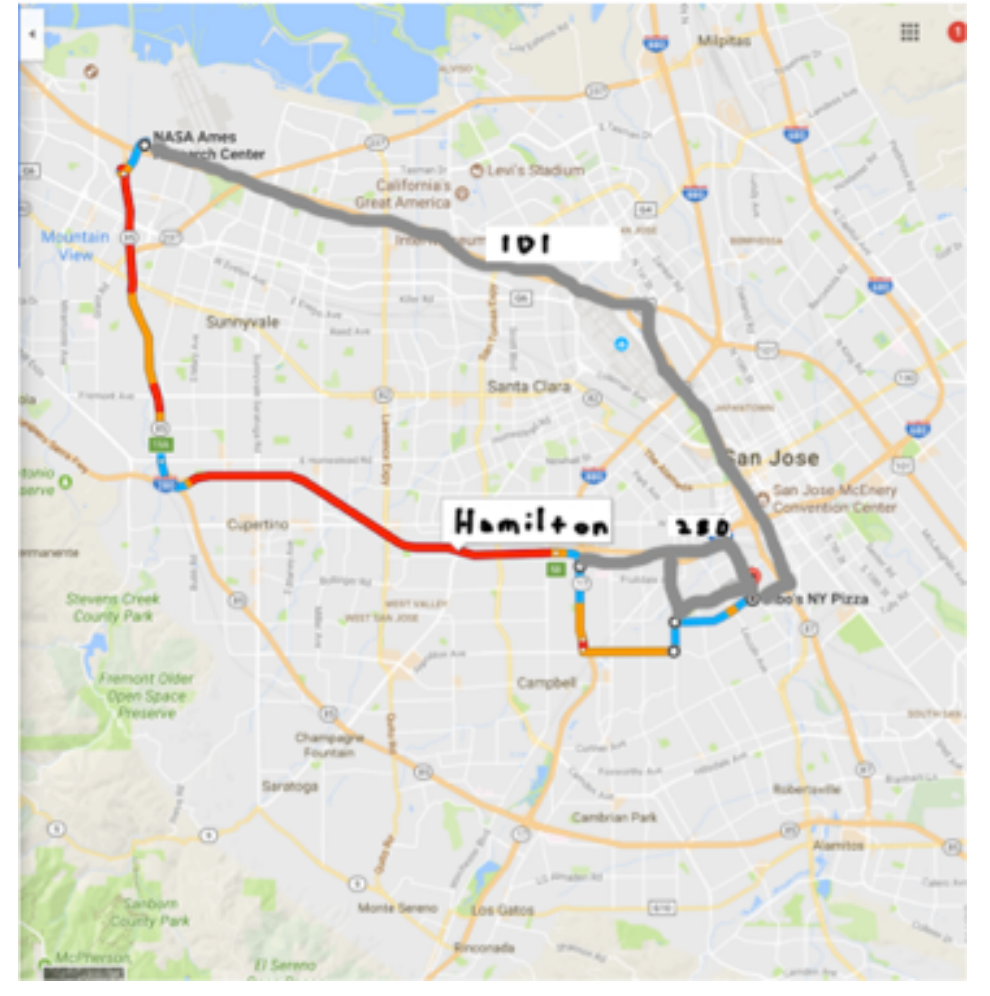




\section{HAT in Photography}

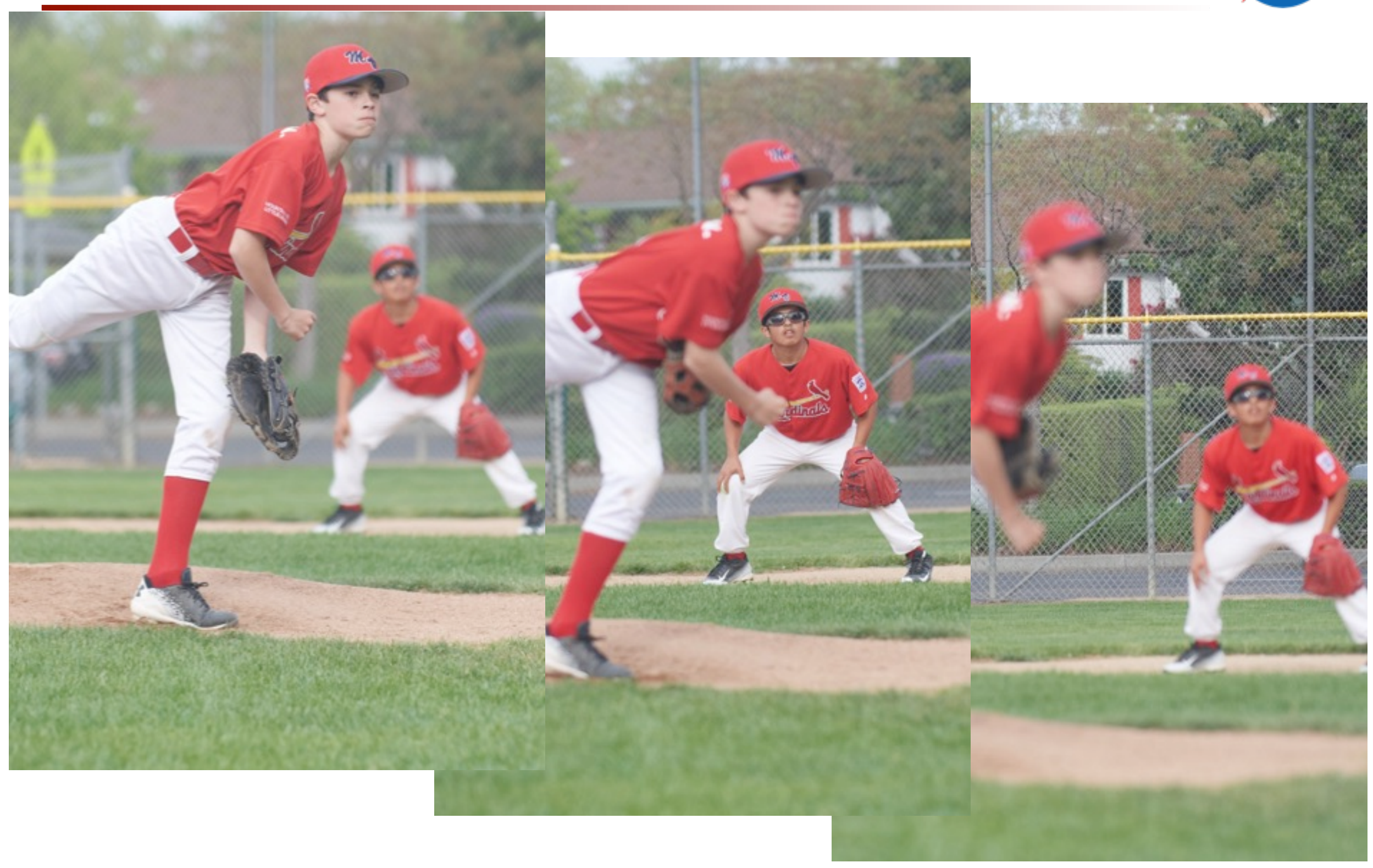




\section{HAT in Photography}

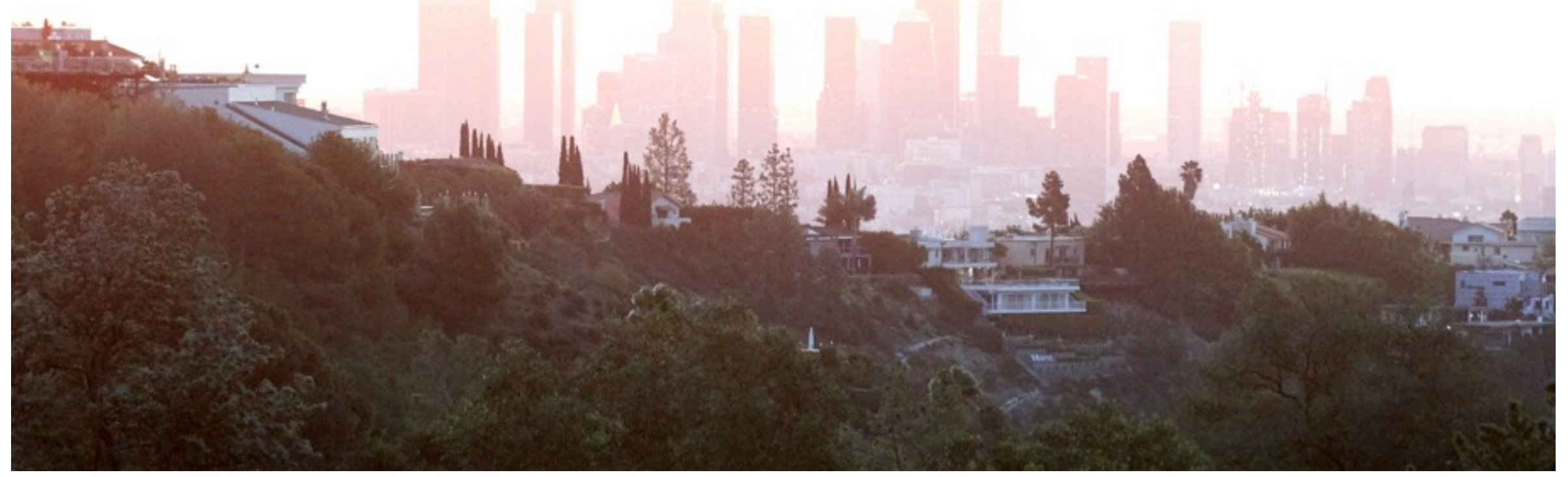


HAT in Photography

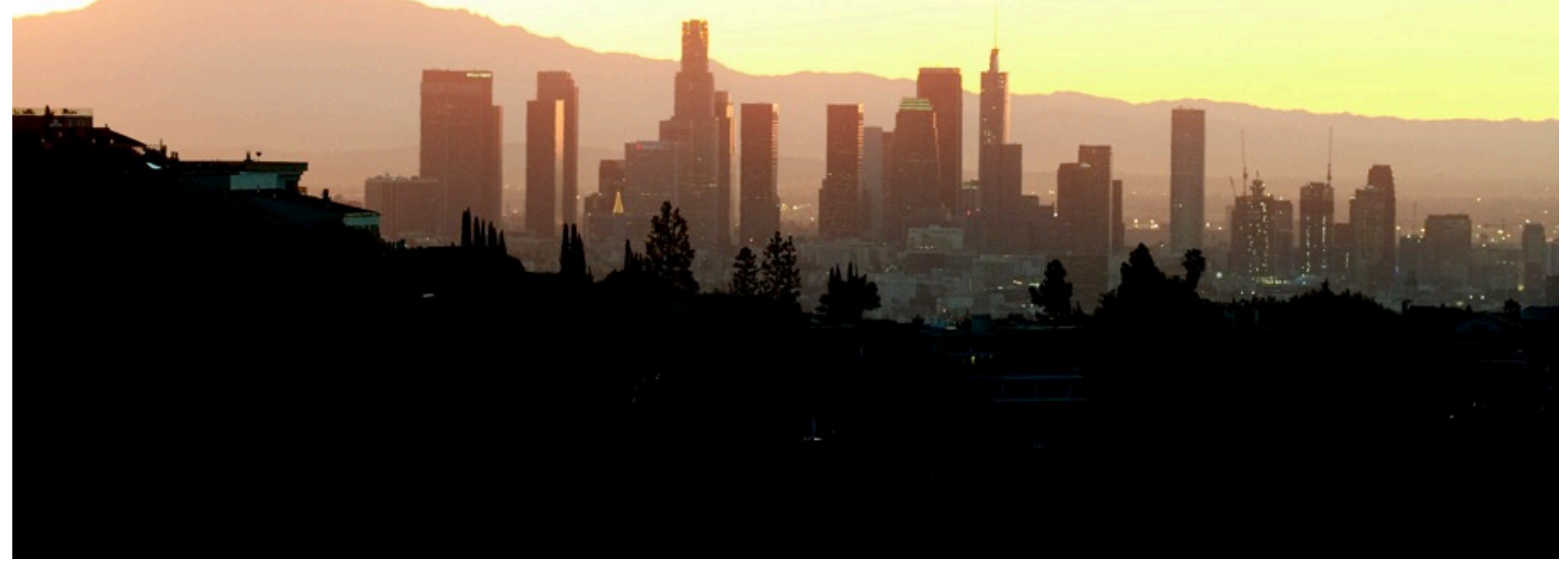


HAT in Photography 


\section{HAT in Photography}

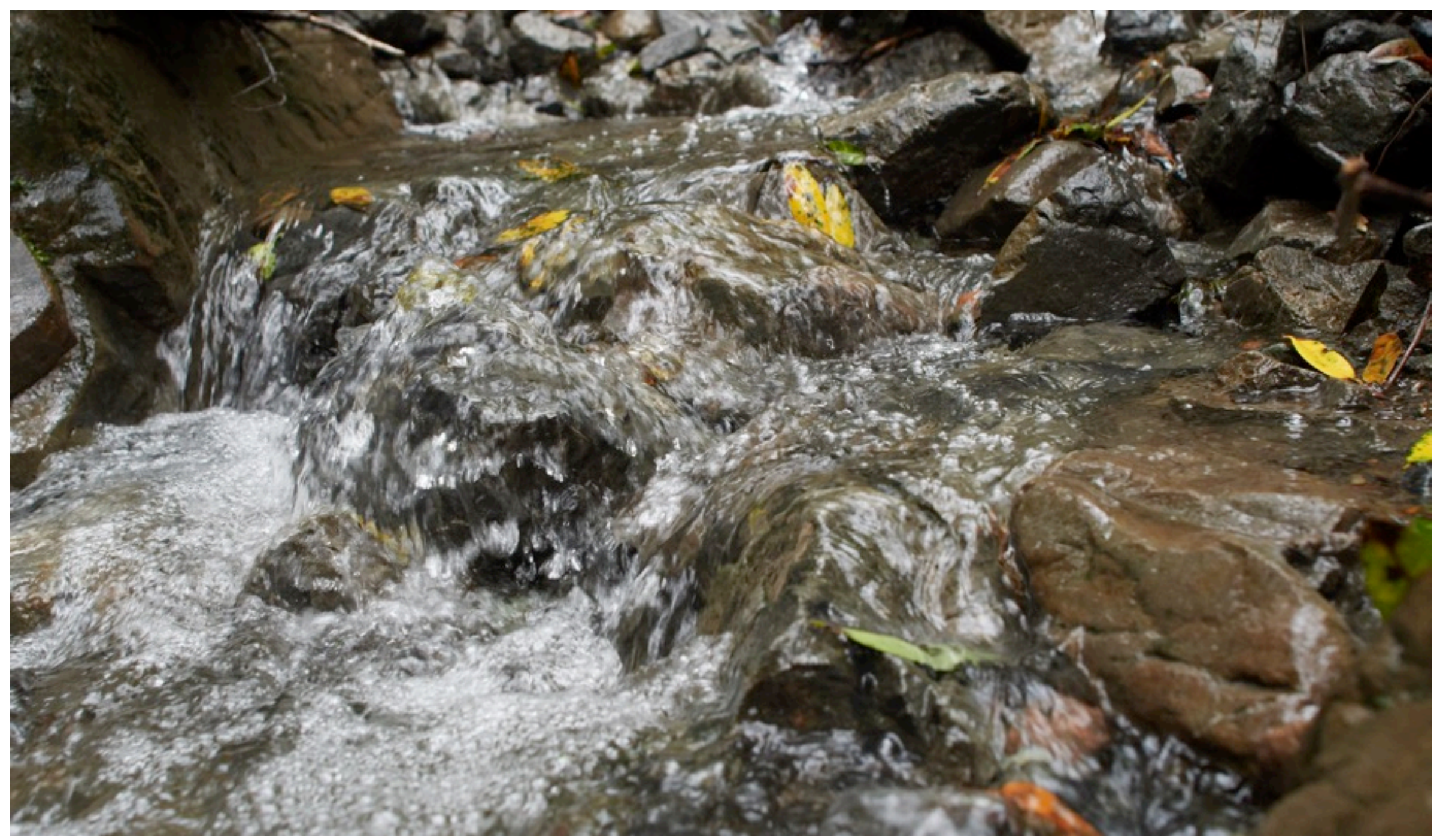




\section{HAT in Photography}

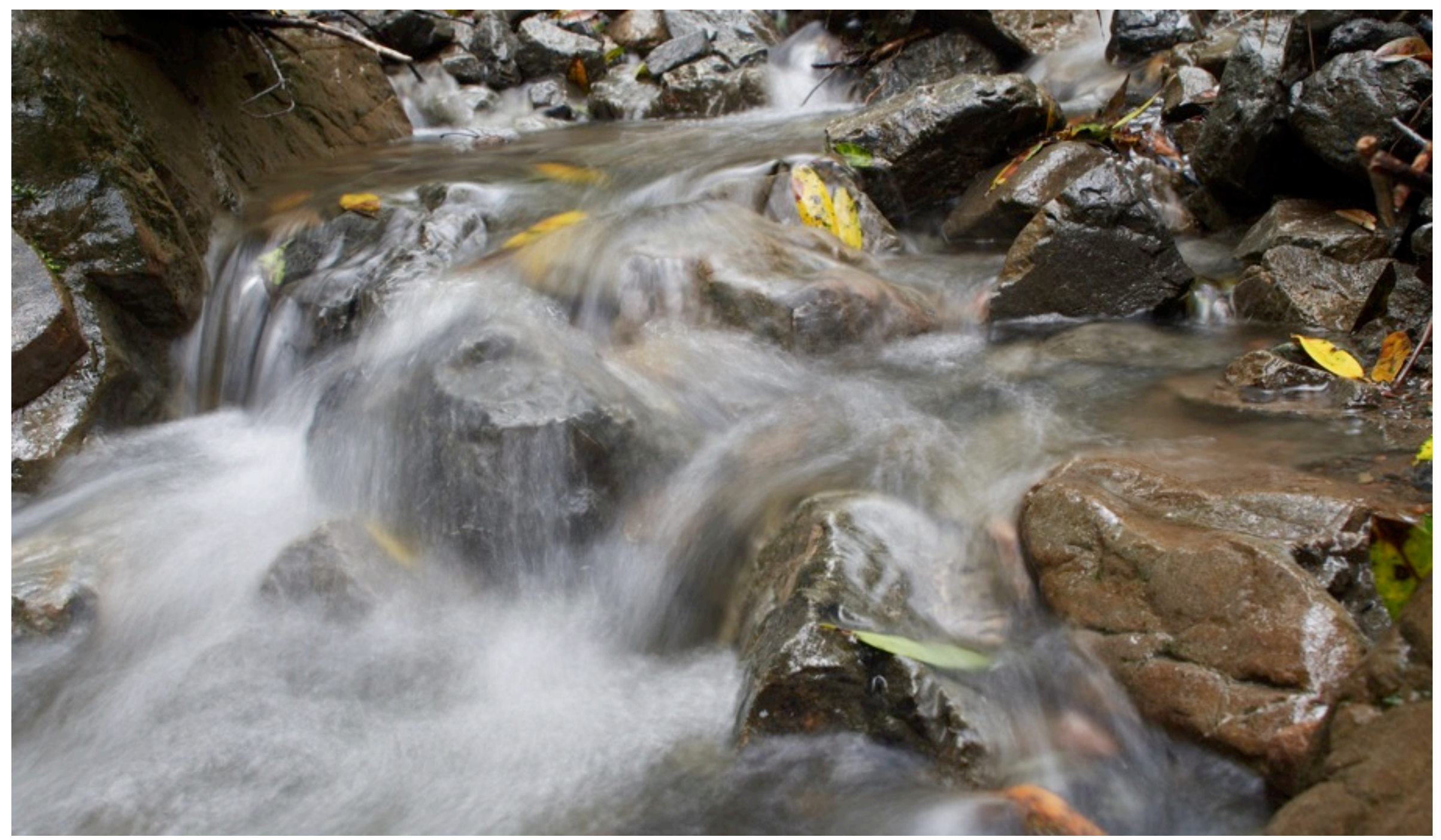




\section{HAT in Photography}






\section{HAT in Photography}

Scene Modes

- Shared Goals $\checkmark$ (sort of)

द. Portrait

- Landscape

5. Child

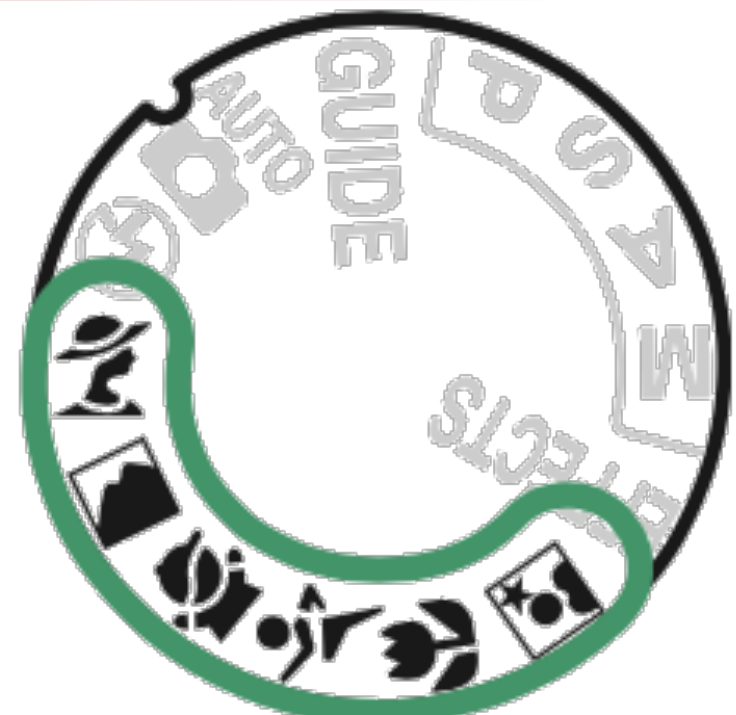

Sports

* Close up

저 Night Portrait 


\section{HAT in Photography}

Scene Modes

- Shared Goals $\checkmark$ (Sort of)

- Transparency $X$

- Shared Plans $\mathbf{X}$

- Etc. $\mathrm{X}$

\section{- Landscape}
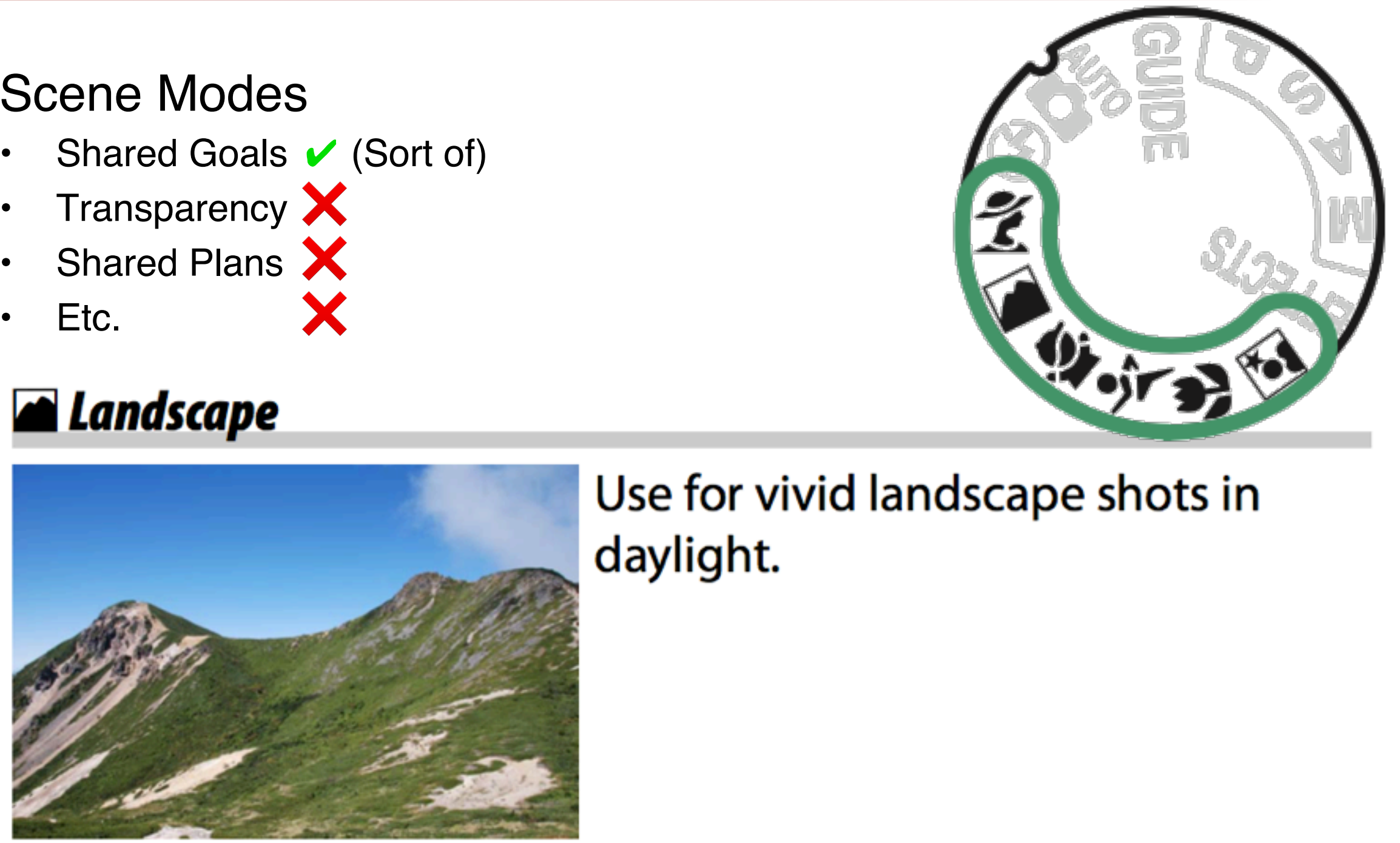

Use for vivid landscape shots in daylight.

\section{Note}

The built-in flash and AF-assist illuminator turn off. 


\section{HAT in Photography}

Scene Modes $\rightarrow$ Plays

- User modifiable plans

- Modifiable offline

- Adaptable online

\section{Bi-Directional Communication}

- User can tell automation goals

- Automation informs user about whether goals are being met
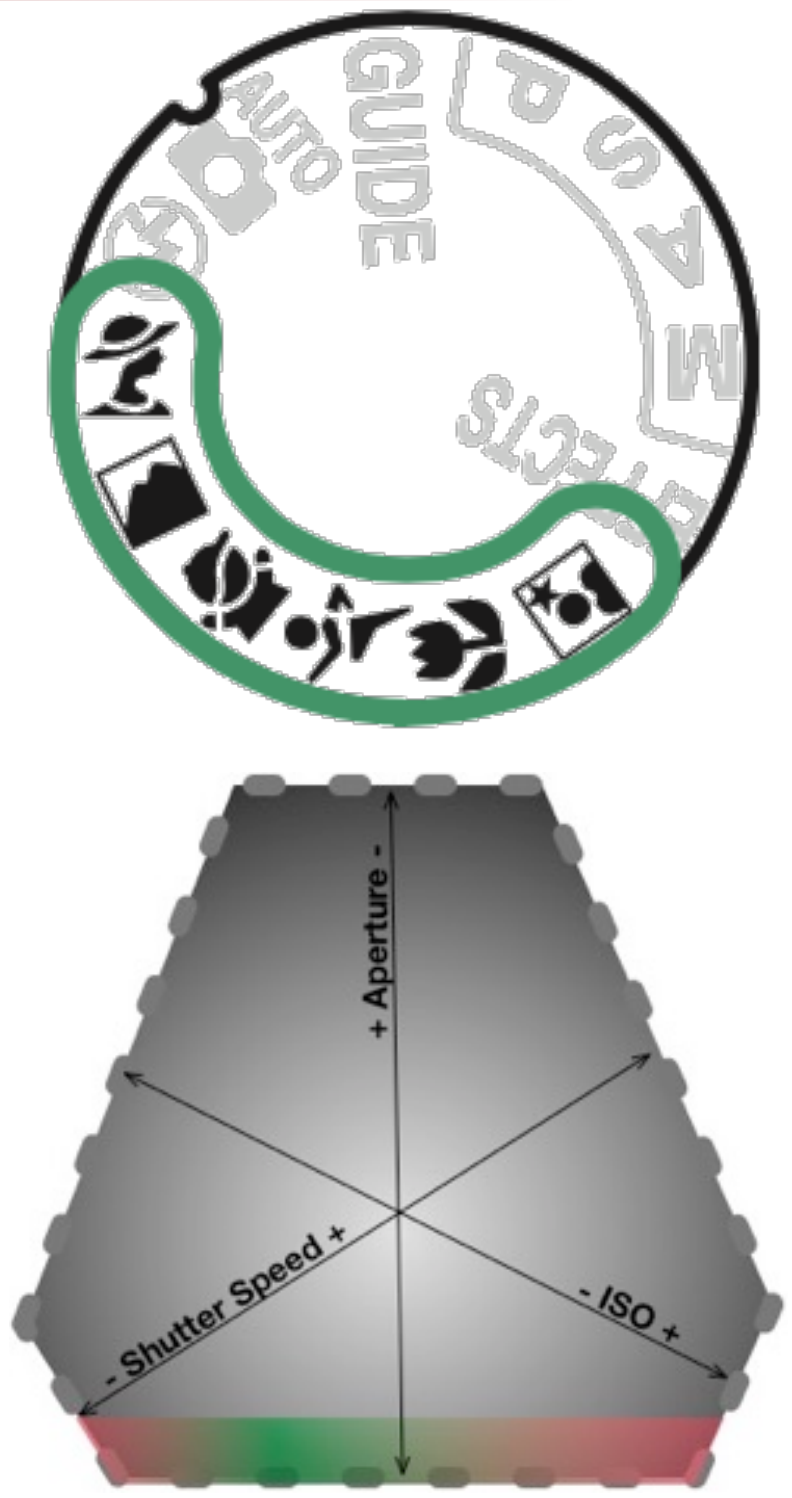


\section{Lessons}

- HAT seems applicable to a wide variety of automation

- Interaction with the automation can profitably be broken into phases based on time constraints

- Real-time

- Time constraints

- Interface constraints

- Still need

- Transparency

- Shared goals

- Delegation

- Etc.

- Offline

- Plays/SOPs

- Move negotiation to less time critical period

- Create a shared language

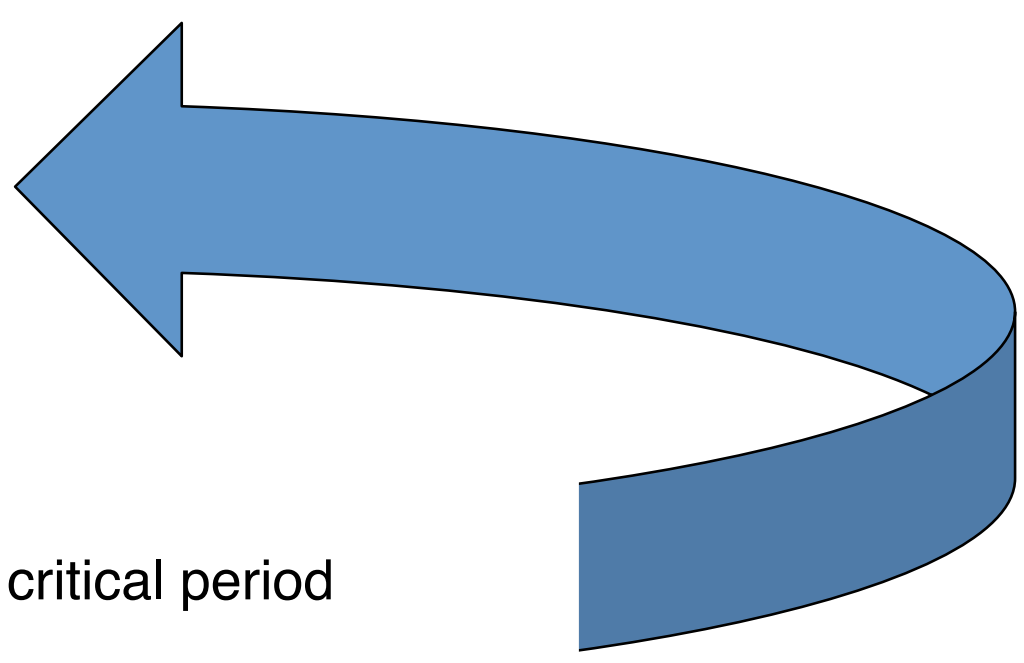




\section{Design Patterns}

- In other domains, people have attempted to capture similar problem-solution pairs using "design patterns"

- Architecture and Urban Planning (Alexander, et al., 1977)

- E.g., Raised Walkways solve the problem of making pedestrians feel comfortable around cars

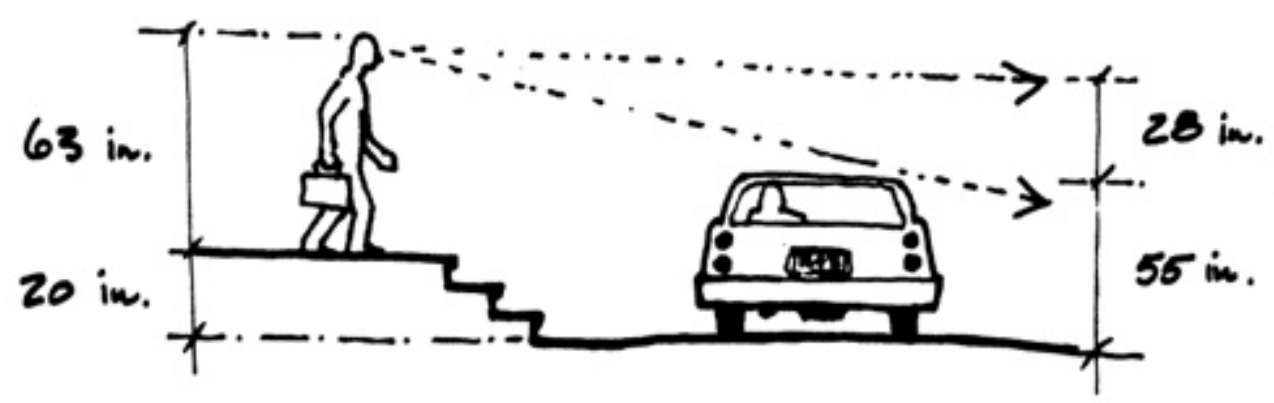

Keep the cars below a person's line of sight.

12 feet wide, at least

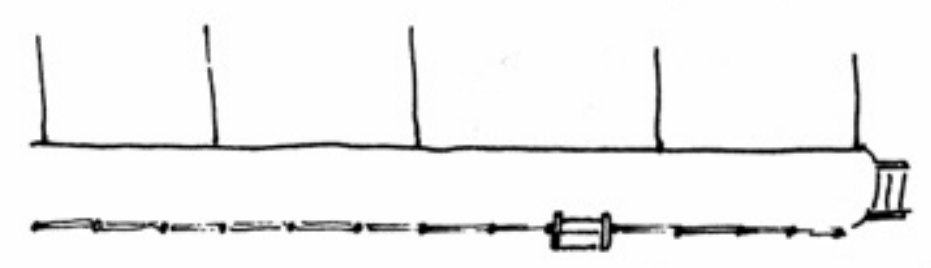

18 inches high

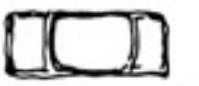




\section{Design Patterns}

- In other domains, people have attempted to capture similar problem-solution pairs using "design patterns"

- Computer Programming (Gamma, et al., 1994)

- E.g., Observers solve the problem of maintaining keeping one object aware of the state of another object

observers

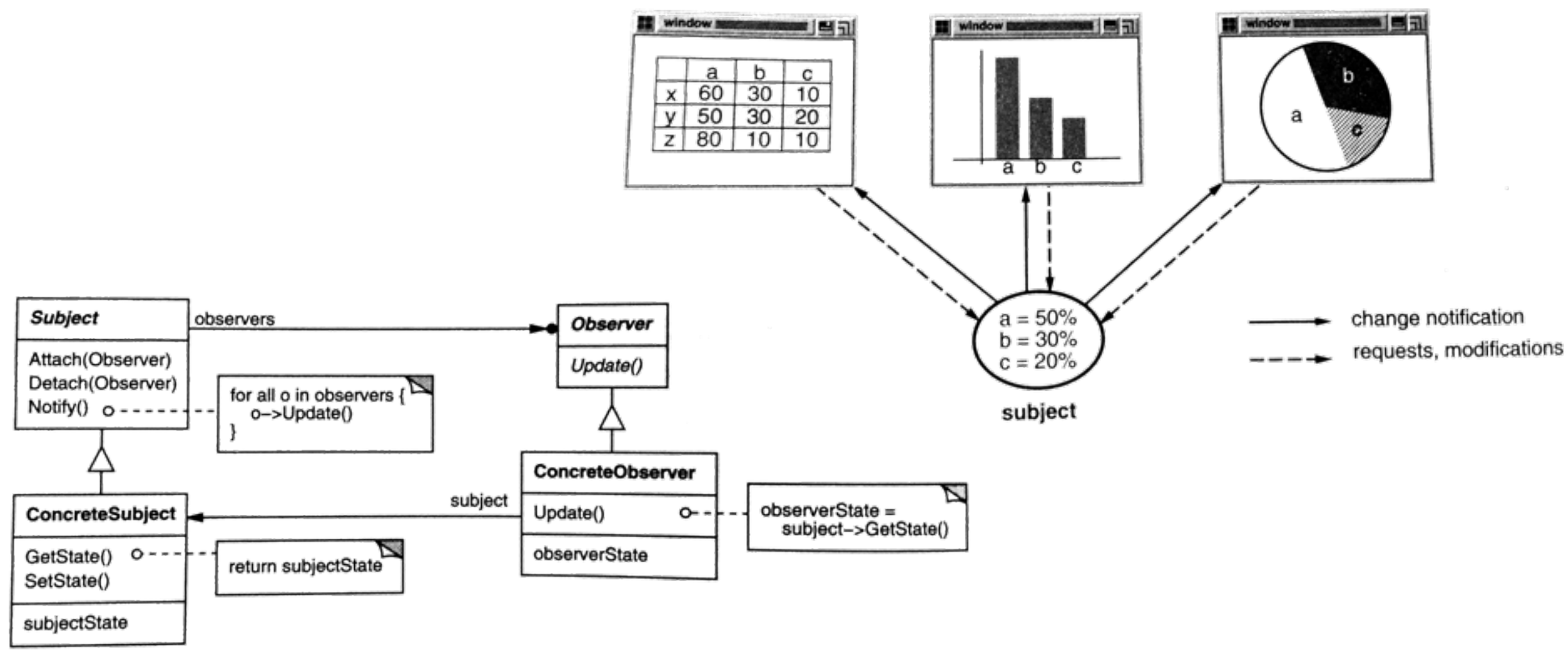




\section{Design Patterns for HAT}

- NATO HAT working group is trying to develop a set of design patterns for HAT

- Working with Gilles Coppin on a Bi-Directional Communication pattern

- Modeled after Gamma et al specifications:

- Intent: Support generation of input from all relevant parties and its integration into decisions

- Motivation: Reduce brittleness of the system by consolidating information and skills

- Applicability: May not be applicable in urgent situations or with automation that lacks structure (e.g., neural networks)

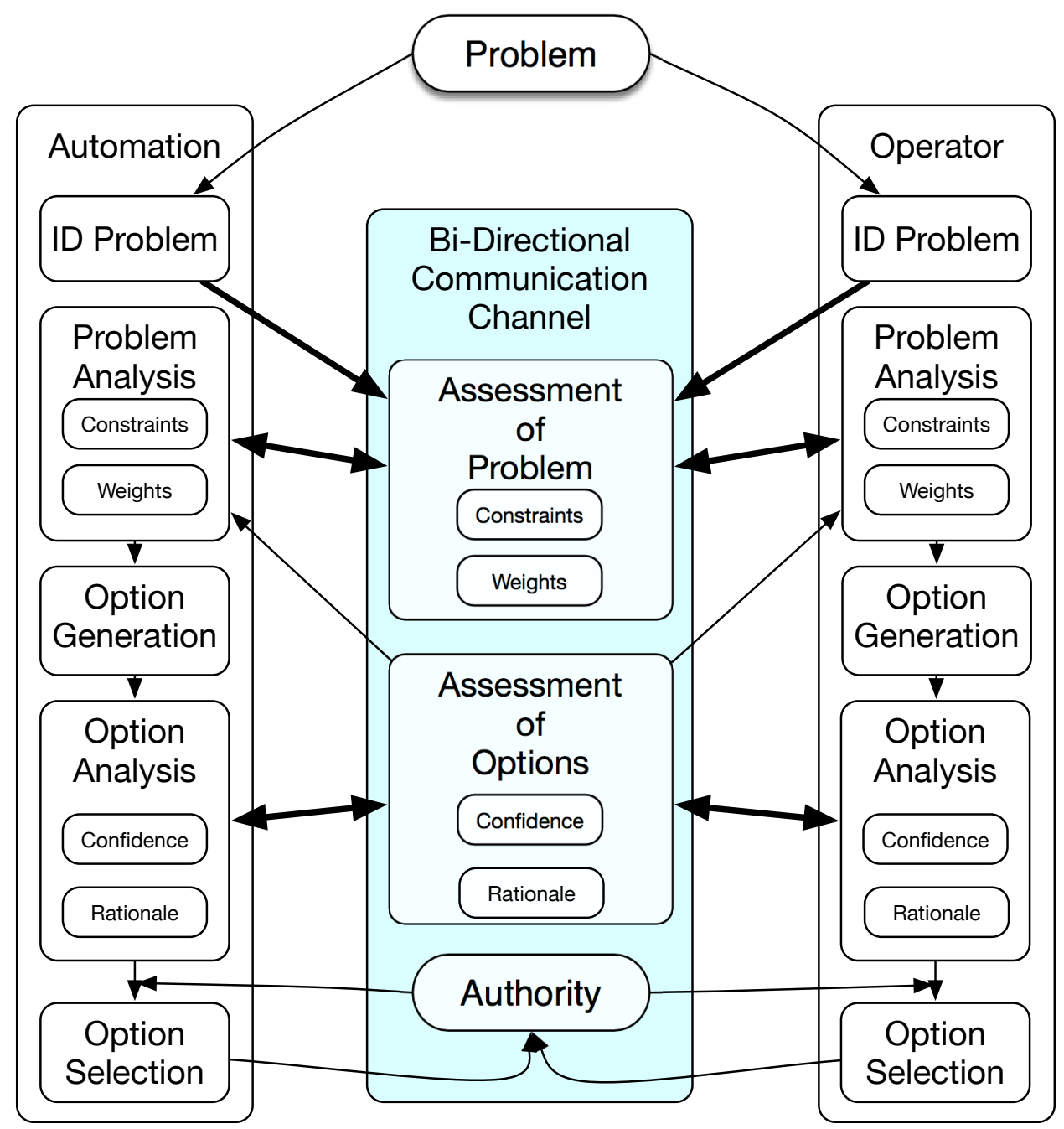




\section{HAT Agent}

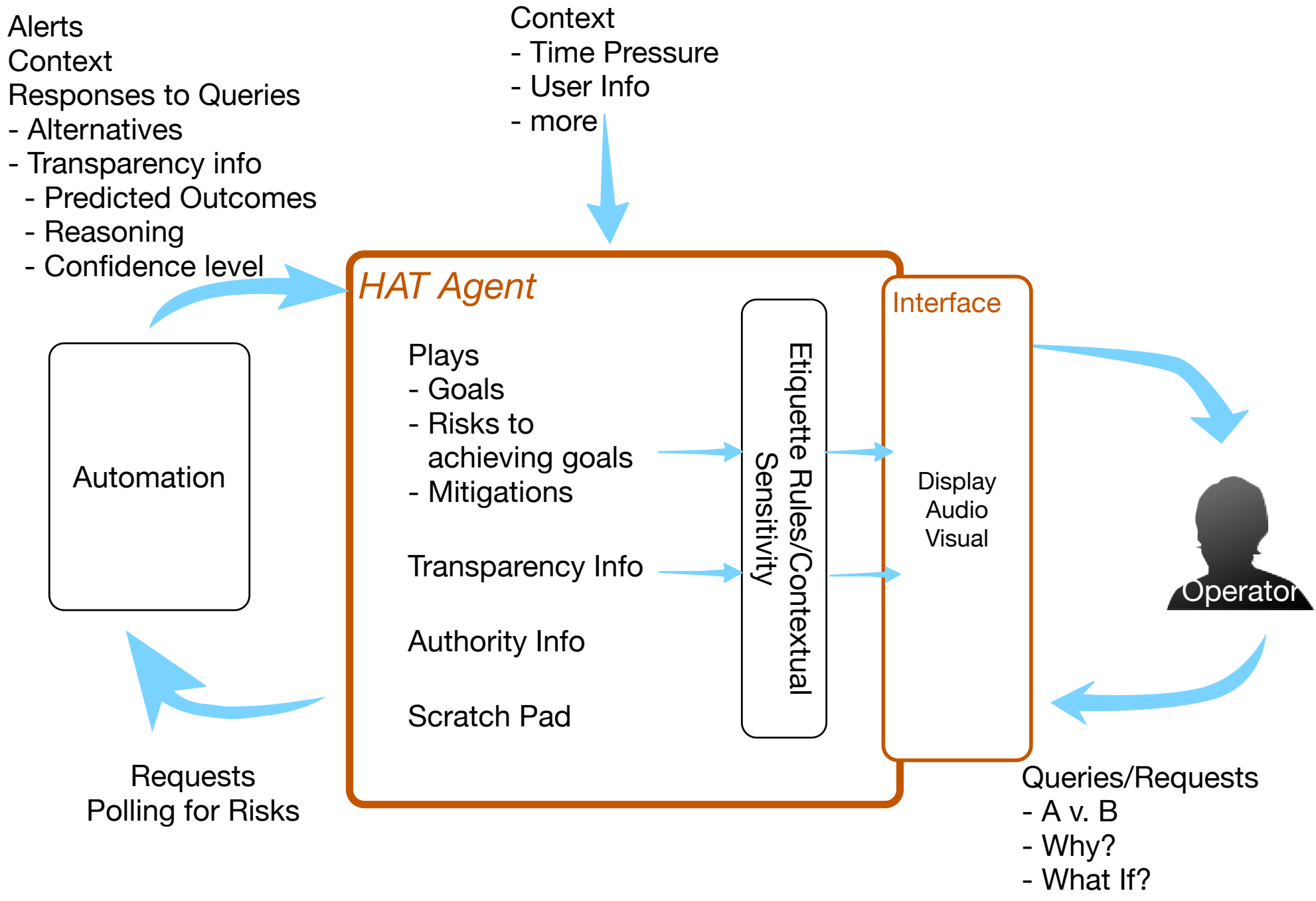


Thank you! 